\title{
Note
}

\section{Antioxidative Activities in Rutin Rich Noodles and Cookies Made with a Trace Rutinosidase Variety of Tartary Buckwheat (Fagopyrum tataricum Gaertn.), 'Manten-Kirari'}

\author{
Koji Ishiguro $^{1 *}$, Toshikazu Morishita ${ }^{1}$, Junzo Ashizawa $^{2}$, Tatsuro Suzuri ${ }^{3}$ and Takahiro Noda ${ }^{1}$ \\ ${ }^{I}$ NARO Hokkaido Agricultural Research Center, 9-4 Shinsei Minami, Memuro, Kasai, Hokkaido 082-0081, Japan \\ ${ }^{2}$ Kobayashi Shokuhin Co.Ltd., Okoppe, Monbetsu, Hokkaido 089-1542, Japan \\ ${ }^{3}$ NARO Kyushu-Okinawa Agricultural Research Center, 2421 Suya, Koshi, Kumamoto 861-1192, Japan
}

Received January 4, 2016 ; Accepted March 28, 2016

\begin{abstract}
A Tartary buckwheat variety, 'Manten-Kirari', which is rich in rutin but lacks bitterness because of trace rutinosidase activity, was recently developed. Rutin content was 1,269 and $1,421 \mathrm{mg} / 100 \mathrm{~g}$ DW in dried noodles and cookies made with $50 \%$ 'Manten-Kirari' flour, respectively. The residual ratio of rutin during preparation of dried noodles and cookies was $\mathbf{9 9 . 3 \%}$ and $\mathbf{8 0 . 6 \%}$, respectively. Hydrophilic antioxidant capacity (H-ORAC) was 149.8 $\mu \mathrm{mol} \mathrm{TE} / \mathrm{g} \mathrm{DW}$ and $209.2 \mu \mathrm{mol} \mathrm{TE} / \mathrm{g} \mathrm{DW}$ in dried noodles and cookies, respectively. The contribution ratio of rutin to H-ORAC was $\mathbf{9 6 . 2 \%}$ and $\mathbf{6 9 . 8 \%}$ in dried noodles and cookies, respectively. These results indicated that the antioxidative activities of dried noodles and cookies made with 'Manten-Kirari' flour were mainly due to the hydrophilic antioxidant rutin. Tartary buckwheat 'Manten-Kirari' is a potentially excellent source of antioxidative food, and is characterized by a high rutin content and minimal bitterness.
\end{abstract}

Keywords: Tartary buckwheat, rutin, rutinosidase, quercetin, ORAC

\section{Introduction}

Buckwheat is cultivated in many countries, including China, Nepal, Russia, Europe and Japan. Buckwheat is a rutin-rich plant and is the only known cereal to contain rutin in the seeds. Rutin is a flavonoid and has many biological functions, such as antioxidative (Jiang et al., 2007; Awatsuhara et al., 2010), strengthening of blood capillaries (Griffith et al., 1944; Shanno, 1946), antihypertensive (Matsubara et al., 1985), $\alpha$-glucosidase inhibitory (Li et al., 2009) and anti-metabolic syndrome (Choi et al., 2006; Hsu et al., 2009; Panchal et al., 2011) activities. Among buckwheat species, Tartary buckwheat (Fagopyrum tataricum Gaertn.) contains an extremely high rutin content in its seeds, $0.5-2 \% \mathrm{w} / \mathrm{w}$, which is approximately 100 -fold higher than that in common buckwheat (Fagopyrum esculentum Moench) (Jiang et al., 2007; Yasuda et al., 1992; Suzuki et al., 2002; Guo et al.,
2011). Tartary buckwheat seeds have been identified as a potential rutin-rich material for food products (Yasuda et al., 1992; Suzuki et al., 2002; Guo et al., 2011); however, with its extremely high rutinosidase activity, rutin-containing buckwheat flour can be hydrolyzed within minutes after the addition of water (Yasuda et al., 1992; Suzuki et al., 2002; Guo et al., 2011; Yasuda et al., 1994). Tartary buckwheat is also known as 'bitter buckwheat'; it has been reported to contain at least three bitter compounds, and the bitterness is the major reason for the limited use of Tartary buckwheat. Rutin hydrolysis is the major contributing factor to bitterness, with quercetin, a rutin hydrolysate, as one of the bitter compounds (Suzuki et al., 2014a; Kawakami et al., 1995). Recently, we developed a novel Tartary buckwheat variety, 'Manten-Kirari', with trace-rutinosidase activity (Suzuki et al., 2014b); the rutinosidase activity in the flour is about two or three 
orders of magnitude less than in other Tartary buckwheat varieties. Additionally, the flour of this variety lacks bitterness. Therefore, we propose that rutin-rich and non-bitter foods can be produced using 'Manten-Kirari' buckwheat flour.

A number of health benefits of buckwheat foods have been reported. The consumption of buckwheat-enriched bread increased the serum antioxidant capacity in humans (Bojnanska et al., 2009), while rutin-enhanced buckwheat noodles reduced the levels of serum total cholesterol and free fatty acids (Qu et al., 2013). In addition, eating buckwheat cookies made with common buckwheat and Tartary buckwheat was associated with a reduction in cholesterol levels, nasal irritation and headache (Wieslander et al., 2011; Wieslander et al., 2012), and intake of Tartary buckwheat cookies with high levels of rutin reduced the serum levels of myeloperoxidase and fatigue symptoms (Wieslander et al., 2011; Wieslander et al., 2012). The effects of buckwheat foods could be largely due to rutin as an antioxidant, since reactive oxygen species (ROS) are implicated in some human diseases, including cancer, atherosclerotic heart disease and Alzheimer's disease. (Ames, 1995; Diaz et al., 1997; Engelhart et al., 2008). Oxygen radical absorbance capacity (ORAC) is a frequently used method in the evaluation of antioxidation (Wu et al., 2004; Watanabe et al., 2012). Previous studies have reported on the antioxidant capacity of Tartary buckwheat and its food products (Ghimeray et al., 2014; Xu et al., 2014; Cho et al., 2014; Zhou et al., 2015). However, there are very few reports on the antioxidant evaluation of buckwheat foods by ORAC (Zielinski et al., 2009), and the antioxidant capacity of buckwheat foods made from Tartary buckwheat 'Manten-Kirari' with trace rutinosidase activity has not been investigated.

In this study, we prepared two kinds of foods, noodles and cookies, using the Tartary buckwheat 'Manten-Kirari' with trace rutinosidase activity. The rutin and quercetin contents in these foods were assessed. Antioxidative activities using the ORAC method as well as DPPH radical scavenging activity were assayed. Contribution ratios of rutin to H-ORAC were also evaluated in dried noodle and cookies.

\section{Materials and Methods}

Reagents and chemicals Fluorescein (sodium salt) (FL) and 6-hydroxy-2,5,7,8-tetramethyl chroman-2-carboxylic acid (Trolox) were from Sigma-Aldrich (St. Louis, MO, USA). 1,1-Diphenyl-2picrylhydrazyl Free Radical (DPPH) was from Tokyo Chemical Industry Co., Ltd. (Tokyo, Japan). Methyl- $\beta$-cyclodextrin (MCD) was obtained from Junsei Chemical Co., Ltd. (Tokyo, Japan). Rutin, quercetin, 2,2'-azobis (2-amidinopropane) dihydro-chloride (AAPH) and all other reagents were purchased from Wako Pure Chemical Ind. (Osaka, Japan).

Flour preparation The Tartary buckwheat variety 'MantenKirari' (trace-rutinosidase variety) was grown in Oumu, Hokkaido, Japan (longitude, $142^{\circ} 58 \mathrm{E}$; latitude, $44^{\circ} 35 \mathrm{~N}$ ) in 2013 . Seeds were sown in June and harvested in late August. Harvested seeds were dried at $40^{\circ} \mathrm{C}$ for one week and then threshed and stored at $4{ }^{\circ} \mathrm{C}$ until used for milling. Tartary buckwheat seeds were milled by the Minami milling company (Sapporo, Japan) using a roll mill. Tartary buckwheat flour was stored at $-20^{\circ} \mathrm{C}$ until used for experiments.

Preparation of noodles and cookies Dried noodles containing $50 \%$ Tartary buckwheat flour to total fresh weight were prepared by Kobayashi Shokuhin Co., Ltd., as follows: $25.0 \mathrm{~kg}$ of Tartary buckwheat 'Manten-Kirari' flour, $23.5 \mathrm{~kg}$ of hard wheat flour and $1.5 \mathrm{~kg}$ of wheat protein (Japan Colloid, Co., Ltd., Tokyo, Japan) were combined. Salt $(0.5 \mathrm{~g})$ and water $(15-16 \mathrm{~g})$ were added using a mixer (Tokyo Menki Co., Ltd., Saitama, Japan) for $10 \mathrm{~min}$. After mixing, the crumbly dough mixture was transferred to a noodlesheeting machine (Tokyo Menki Co., Ltd.). The sheet was cut into noodles, and the cut noodles were air dried until a water content of $15.0 \%$ was reached. They were milled and passed through a $250 \mu \mathrm{m}$ sieve before storage at $-30^{\circ} \mathrm{C}$ until analysis.

Dried noodles were boiled in $4 \mathrm{~L}$ of water for $6 \mathrm{~min}$ and then rinsed with cold water. Boiled noodles were freeze-dried before storage at $-30^{\circ} \mathrm{C}$ until their use in the rutin and quercetin content and ORAC assays.

The cookies containing 50\% Tartary buckwheat flour to total fresh weight were prepared as follows: $38 \mathrm{~g}$ of Tartary buckwheat 'Manten-Kirari' flour, $13 \mathrm{~g}$ of sugar, $19.5 \mathrm{~g}$ of raw egg, $4.65 \mathrm{~g}$ of fermented butter without salt and $0.25 \mathrm{~g}$ of salt were mixed. The dough was stored at $4^{\circ} \mathrm{C}$ for 1 hour before being cut into cookies weighing $15 \mathrm{~g}$ each, which were then baked at $160^{\circ} \mathrm{C}$ for $15 \mathrm{~min}$. Baked cookies were milled and passed through a $250 \mu \mathrm{m}$ sieve and stored at $-30^{\circ} \mathrm{C}$ until analysis.

Rutin and quercetin contents Rutin and quercetin were extracted from $1.0 \mathrm{~g}$ of samples with $50 \mathrm{~mL}$ of $80 \%$ ethanol at $80^{\circ} \mathrm{C}$ for two hours with intermittent mixing. After centrifugation at $3,000 \mathrm{~g}$ for $10 \mathrm{~min}$, the supernatant was diluted 100 times with $80 \%$ ethanol and filtered through a $0.45 \mu \mathrm{m}$ membrane; the rutin and quercetin contents were determined by HPLC (Suzuki et al., 2002). The HPLC system consisted of two pumps (model LC-20AD; Shimadzu, Kyoto, Japan), an autoinjector (model SIL-20AC; Shimadzu), a column oven (model CTO-20AC; Shimadzu) and a photodiode array detector (model SPD-M20A; Shimadzu). A reversed phase column was used (150 x $2 \mathrm{~mm}$ i.d., $3 \mu \mathrm{m}$, Cadenza CD-C18; Imtakt, Co., Ltd., Kyoto, Japan). The mobile phase consisted of $7.5 \%(\mathrm{v} / \mathrm{v})$ acetonitrile containing $0.1 \%(\mathrm{v} / \mathrm{v})$ TFA (A) and $50 \%(\mathrm{v} / \mathrm{v})$ acetonitrile containing $0.1 \%(\mathrm{v} / \mathrm{v})$ TFA (B). Elution was performed using a $35 \%$ solution of $\mathrm{B}$, at a flow rate of $0.3 \mathrm{~mL} /$ min for $18 \mathrm{~min}$. The column oven was set at $40^{\circ} \mathrm{C}$ and the injection volume was $2 \mu \mathrm{L}$. Rutin and quercetin were identified by the retention time and the UV-vis spectra of standards. Quantification of rutin and quercetin was carried out according to an external standard method using calibration curves based on detection at $360 \mathrm{~nm}$. Rutin and quercetin were quantified as mg per $100 \mathrm{~g}$ of dry 
Table 1. Rutin and quercetin contents in flour, dried noodles and cookies containing 50\% Tartary buckwheat 'Manten-Kirari'

\begin{tabular}{|c|c|c|c|}
\hline Foods & $\begin{array}{l}\text { Rutin content } \\
\text { (mg/100 g DW) }\end{array}$ & $\begin{array}{l}\text { Quercetin content } \\
(\mathrm{mg} / 100 \mathrm{~g} \mathrm{DW})\end{array}$ & Residual rutin (\%) \\
\hline Flour & $2,712 \pm 51.7$ & n.d. & \\
\hline Dried noodle & $1,269 \pm 8.6$ & $4.4 \pm 2.9$ & $99.3 \pm 0.4$ \\
\hline Cookie & $1,421 \pm 39.8$ & $169 \pm 15.1$ & $80.6 \pm 1.8$ \\
\hline
\end{tabular}

Data are presented as mean $\pm \mathrm{SE}(\mathrm{n}=8)$. n.d., not detected.

weight (DW). Residual rutin rates after preparation of dried noodles and cookies were calculated as the molar ratio of rutin to the sum of rutin and quercetin.

DPPH radical scavenging activity DPPH radical scavenging activity was assayed as previously described (Ishiguro et al., 2007) with the following modifications: samples $(100 \mathrm{mg})$ were vigorously mixed in $10 \mathrm{~mL}$ of $80 \%$ ethanol and heated in a boiling water bath for $5 \mathrm{~min}$. The extract was diluted with $80 \%$ ethanol to various concentrations. Diluted samples $(50 \mu \mathrm{L})$ were transferred to a 96-well microplate, and $50 \mu \mathrm{L}$ of 2-morpholinoethanesulfonic acid (MES) buffer (200 mM MES, pH 6.0), $50 \mu \mathrm{L}$ of $20 \%$ ethanol and $50 \mu \mathrm{L}$ of DPPH solution ( $800 \mu \mathrm{M}$ in ethanol) were added. After allowing the reaction to proceed for $20 \mathrm{~min}$, absorbance at $520 \mathrm{~nm}$ was measured using a microplate reader (Infinite M200 PRO; TECAN Japan Co., Ltd., Kanagawa, Japan). Reaction solutions without DPPH were used as color controls, and Trolox was used as a standard. $\mathrm{A}_{520}$ values were plotted against the diluted sample, and a linear decrease in $\mathrm{A}_{520}$ of the DPPH radical was recorded. DPPH radical scavenging activity was expressed as $\mu$ mol Trolox equivalents (TE) per gram of DW.

Hydrophilic and lipophilic oxygen radical absorbance capacities (H-ORAC and L-ORAC) Lipophilic and hydrophilic components in noodles and cookies were extracted according to the method of Wu et al. (2004) with slight modification. Five grams of sea sand were added to $1 \mathrm{~g}$ of either noodle or cookie sample, and initial extraction was performed with $10 \mathrm{~mL}$ of hexane/ dichloromethane to extract the lipophilic components. Supernatants were collected after centrifugation at $3,000 \mathrm{~g}$ for $10 \mathrm{~min}$. This step was repeated again before the supernatants were dried by rotary evaporator and redissolved in $10 \mathrm{~mL}$ of acetone. The extracts were then diluted 10- and 20-times by 7\% MCD, and used in the L-ORAC assays. The precipitates, after hexane/dichloromethane extraction, were dried under nitrogen flow before the addition of $10 \mathrm{~mL}$ of acetone/water/acetic acid (70:29.5:0.5, AWA), and vortexing for $30 \mathrm{~s}$, followed by sonication at $37^{\circ} \mathrm{C}$ for $5 \mathrm{~min}$. After cooling at room temperature for $10 \mathrm{~min}$, samples were centrifuged at $3,000 \mathrm{~g}$ for $10 \mathrm{~min}$. This extraction step was repeated before supernatants were collected and made up to a final volume of $25 \mathrm{~mL}$. The AWA extracts were diluted 100-, 200-, 400- and 800 -times using assay buffer $(75 \mathrm{mM}$ potassium phosphate buffer (pH 7.4)) for use in the H-ORAC assays. H-ORAC and L-ORAC assays were measured according to the method of MikamiKonishide et al. (2013). Thirty-five microliters of diluted extracts were transferred, in duplicate, to 96-well microplates, followed by the addition of $115 \mu \mathrm{L}$ of $110.7 \mathrm{nM}$ FL solution in assay buffer. After a pre-incubation of $15 \mathrm{~min}$ at $37^{\circ} \mathrm{C}$, fluorescence intensity (Ex: $485 \mathrm{~nm}$, Em: $530 \mathrm{~nm}$ ) was measured using a microplate reader (Infinite M200 PRO; TECAN Japan Co., Ltd.). For H-ORAC, $50 \mu \mathrm{L}$ of $31.7 \mathrm{mM}$ AAPH assay buffer and for L-ORAC, $50 \mu \mathrm{L}$ of $63.4 \mathrm{mM}$ AAPH was added to each sample before measurement of fluorescence intensity for $90 \mathrm{~min}$ for H-ORAC and $120 \mathrm{~min}$ for L-ORAC at 2 min intervals. Data are expressed as $\mu$ mol TE per gram. The contribution ratio of rutin or quercetin to the H-ORAC value was calculated as follows:

Contribution $(\%)=(\mathrm{H}-\mathrm{ORAC}$ value of rutin or quercetin $\mathrm{x}$ rutin or quercetin content in sample) / (H-ORAC value of sample) $\mathrm{x} 100$ $\cdots$ Eq. 1

Statistical analysis Eight replications were performed for all analyses and data are shown as average \pm standard error. Student's $t$-test was used to show the differences between the rutin, quercetin and H-ORAC values before and after cooking the dried noodles.

\section{Results and Discussion}

Rutin and quercetin contents of noodles and cookies containing Tartary buckwheat flour with trace rutinosidase activity Dried noodles and cookies containing 50\% Tartary buckwheat 'MantenKirari' flour retained $99.3 \%$ and $80.6 \%$ of rutin during preparations, respectively (Table 1). Only small amounts of quercetin were produced by hydrolyzation of rutin during noodle and cookie preparation because of the trace amount of rutinosidase in the 'Manten-Kirari' flour; quercetin was not originally present in the flour. Suzuki et al. (2015) reported that the residual rutin ratio in dough prepared from 'Manten-Kirari' after the addition of water slightly and slowly decreased with increasing time and water to flour ratio, while in another Tartary buckwheat flour with normal rutinosidase activity, most of the rutin rapidly decomposed to quercetin on addition of water. It is suggested that rutin degradation in the dough is minimized by the trace rutinosidase activity of 'Manten-Kirari' during dried noodle and cookie preparation. The higher water content and increased time of dough preparation could have resulted in the increased degradation of rutin in cookies compared with noodles. 
Table 2. DPPH radical scavenging activities, H-ORAC and L-ORAC values in dried noodles and cookies containing 50\% Tartary buckwheat 'Manten-Kirari'

\begin{tabular}{|c|c|c|c|}
\hline Foods & $\begin{array}{c}\text { DPPH radical } \\
\text { scavenging } \\
(\mu \mathrm{mol} \text { TE/g DW) }\end{array}$ & $\begin{array}{c}\text { H-ORAC } \\
(\mu \mathrm{mol} \text { TE/g DW })\end{array}$ & $\begin{array}{c}\text { L-ORAC } \\
(\mu \mathrm{mol} \mathrm{TE} / \mathrm{g} \mathrm{DW})\end{array}$ \\
\hline Dried noodle & $38.3 \pm 0.5$ & $149.8 \pm 2.9$ & - \\
\hline Cookie & $50.7 \pm 0.8$ & $209.2 \pm 10.5$ & $6.8 \pm 0.5$ \\
\hline
\end{tabular}

Data are presented as mean $\pm \mathrm{SE}(\mathrm{n}=8)$. -, below limit of detection.

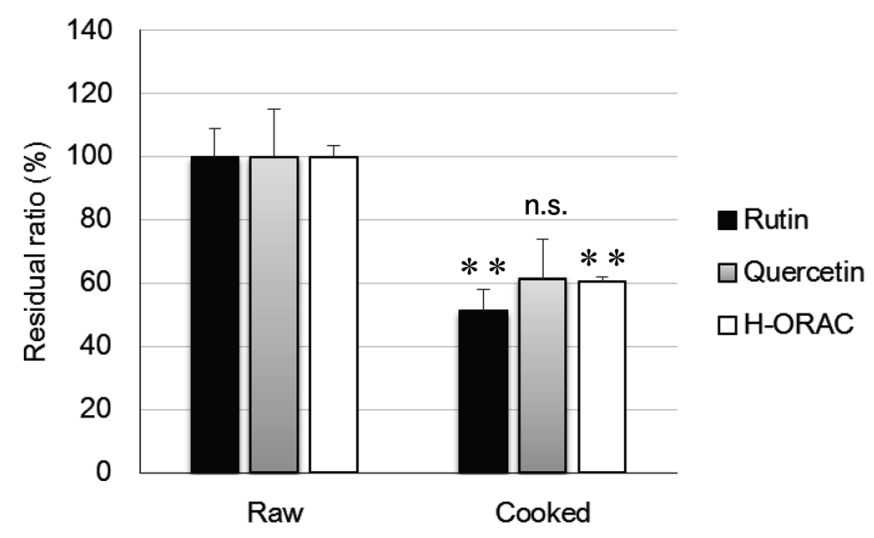

Fig. 1. Residual ratio of rutin, quercetin and H-ORAC value of cooked noodles after boiling for $6 \mathrm{~min}$. The boxes represent the relative contents of rutin and quercetin, or relative $\mathrm{H}$-ORAC value. Vertical bars represent SE $(\mathrm{n}=5)$.** Indicates statistical differences between raw and cooked noodles at a $1 \%$ level, according to the Student's $t$-test; n.s., not significant.

A substantial amount of rutin present in dried noodles made using common buckwheat was reduced by boiling (Ohara et al., 1989). Therefore, the ratios of residual rutin and quercetin were evaluated after cooking dried noodles made using Tartary buckwheat 'Manten-Kirari' in boiling water. The rutin content significantly reduced to $51.3 \%$ and quercetin content reduced to $61.3 \%$ (Fig. 1). The reductions were considered to be due to losses to the boiling water during cooking.

Previous reports measured the rutin content of noodles made with $70 \%$ common buckwheat flour as $7.84 \mathrm{mg} / 100 \mathrm{~g} \mathrm{DW}$ and precooked groats as $8.79 \mathrm{mg} / 100 \mathrm{~g} \mathrm{DW}$ (Kreft et al., 2006); bread containing 30\% common buckwheat had between $3.47 \mathrm{mg} / 100 \mathrm{~g}$ DW and $3.82 \mathrm{mg} / 100 \mathrm{~g}$ DW rutin (Bojnanska et al., 2009), while the concentrations of rutin and quercetin were $253 \mathrm{mg} / 100 \mathrm{~g} \mathrm{DW}$ and $163 \mathrm{mg} / 100 \mathrm{~g} \mathrm{DW}$, respectively, in cookies made with $50 \%$ other Tartary buckwheat flour (Wieslander et al., 2011). The foods made with 'Manten-Kirari' flour in this study had much higher rutin contents compared with foods made with common and other Tartary buckwheats.

Antioxidative activities of noodles and cookies containing Tartary buckwheat flour with trace rutinosidase activity In order to evaluate the antioxidative activities of the noodles and cookies made with Tartary buckwheat 'Manten-Kirari', DPPH radical scavenging activity and ORAC assays were performed. The H-ORAC value was about 4 times higher than the DPPH radical scavenging activity (Table 2). The L-ORAC values in dried noodles were below the limit of detection, and those in cookies were considerably low compared with H-ORAC (Table 2). Most of the antioxidants showed higher antioxidative activity in the H-ORAC assay compared to the DPPH assay (Watanabe et al., 2009), and the same trend in the difference between DPPH and H-ORAC assays was observed in other foodstuffs (Takebayashi et $a l ., 2013)$. This trend is probably due to the difference in the antioxidative activity of the antioxidants (rutin and quercetin) in dried-noodles and cookies containing 'Manten-Kirari' flour between H-ORAC and DPPH assays. The contribution ratio of rutin to $\mathrm{H}$-ORAC was $96.2 \%$ and that of quercetin was $0.8 \%$ in dried noodles, derived from the ORAC values of rutin $(10,240 \mu \mathrm{mol}$ TE/g DW) and quercetin $(27,045 \mu \mathrm{mol}$ TE/g DW). In cookies, the contribution of rutin was $69.8 \%$ and that of quercetin was $22.6 \%$. These results confirmed that the antioxidative activities in dried noodles and cookies made with Tartary buckwheat 'Manten-Kirari' flour were mainly due to the hydrophilic antioxidant rutin.

Mikami-Konishida et al. (2013) reported that H-ORAC values ranged from 1.94 to $298.3 \mu \mathrm{mol} \mathrm{TE} / \mathrm{g}$ fresh weight (FW) in 71 crops cultivated in Japan. The higher ORAC values were mainly measured in leaf and stem vegetables, such as mulukhiya (Corchorus olitorius) and perilla (Perilla frutescens). Takebayashi et al. (2013) reported that the H-ORAC values of 23 vegetables and 13 fruits commonly consumed in Japan ranged from 1.63 to $66.07 \mu \mathrm{mol} \mathrm{TE} / \mathrm{g} \mathrm{FW}$ and from 1.58 to $33.47 \mu \mathrm{mol} \mathrm{TE} / \mathrm{g} \mathrm{FW}$, respectively. The average $\mathrm{H}-\mathrm{ORAC}$ values of the 23 vegetables and 13 fruits was $6.95 \mu \mathrm{mol} \mathrm{TE} / \mathrm{g} \mathrm{FW}$ and $12.23 \mu \mathrm{mol} \mathrm{TE} / \mathrm{g} \mathrm{FW}$, respectively. The H-ORAC values of raw whole seeds and groats of common buckwheat were $124.55 \mu \mathrm{mol} \mathrm{TE} / \mathrm{g} \mathrm{DW}$ and $95.01 \mu \mathrm{mol} \mathrm{TE} / \mathrm{g} \mathrm{DW}$, respectively (Zielinski et al., 2009). In comparison, the H-ORAC values of noodles $(136.3 \mu \mathrm{mol} \mathrm{TE} / \mathrm{g}$ FW) and cookies $(189.0 \mu \mathrm{mol}$ TE/g FW) containing 50\% Tartary buckwheat 'Manten-Kirari' flour were extremely high, even though in boiled noodles the value significantly decreased to $60.5 \%$ of that in dried noodles, with a corresponding decrease in rutin and quercetin (Fig. 1).

Takebayashi et al. (2013) reported that the estimated daily intake of hydrophilic antioxidants was $4,423 \mu \mathrm{mol}$ TE per day, which is about $10 \%$ lower than the Japanese government recommendations of $4,879 \mu \mathrm{mol} \mathrm{TE} / \mathrm{g} \mathrm{FW}$. Our results show that 
boiled noodles containing 50\% 'Manten-Kirari' flour provides $65.5 \mu \mathrm{mol}$ TE/g FW. Hence, the intake of $100 \mathrm{~g}$ of dried noodles made with $50 \%$ 'Manten-Kirari' flour after boiling would result in the consumption of $6,550 \mu \mathrm{mol}$ TE of hydrophilic antioxidants. We also estimate that $50 \mathrm{~g}$ (4 pieces) of cookies containing $50 \%$ 'Manten-Kirari' flour could provide 7,365 $\mu \mathrm{mol}$ TE of hydrophilic antioxidants. These results indicate that noodles and cookies made from the novel Tartary buckwheat variety 'Manten-Kirari' could contribute to an increase in antioxidant intake.

Rutin is the main hydrophilic antioxidant in noodles and cookies made using the Tartary buckwheat 'Manten-Kirari'. Trace rutinosidase activity in 'Manten-Kirari' results in a higher rutin residual ratio and non-bitterness in the foods. Intake of abundant hydrophilic antioxidants (mainly rutin) from Tartary buckwheat 'Manten-Kirari' would be relatively easily accomplished, since soba-noodle is a popular menu choice in Japan. In addition, the non-bitter taste of this noodle would spur consumption. Driednoodles made with 'Manten-Kirari' are now available to purchase, and human intervention studies of these foods have just started. Beneficial health effects of foods containing the Tartary buckwheat 'Manten-Kirari' are expected.

Acknowledgements This work was supported by a grant from the Research Project on Development of Agricultural Products and Foods with Health-promoting benefits (NARO), Japan. We thank Ms. M. Saito, Ms. K. Fujii, Ms. M. Hayashida, and Ms. T. Ando for technical assistance.

\section{References}

Ames, B.N., Gold, L.S., and Willet, W.C. (1995). The causes and prevention of cancer. Proc. Natl. Acad. Sci. U.S.A., 92, 5258-5265.

Awatsuhara, R., Harada, K., and Maeda, T. (2010). Antioxidative activity of the buckwheat polyphenol rutin in combination with ovalbumin. Molecular Med. Rep., 3, 121-125.

Bojnanska, T., Francakova, H., Chlebo, P., and Vollmannova, A. (2009). Rutin content in buckwheat enriched bread and influence of its consumption on plasma total antioxidant status. Czech J. Food Sci., 27, s236-s240.

Cho, Y.J., Bae, I.Y., Inglett, G.E., and Lee, S. (2014). Utilization of tartary buckwheat bran as a source of rutin and its effect on the rheological and antioxidant properties of wheat-based products. Ind. Crop Prod., 61, 211-216

Choi, I., Park, Y., Choi, H., and Lee, E.H. (2006). Anti-adipogenic activity of rutin in 3T3-L1 cells and mice fed with high-fat diet. BioFactors, 26, 273-281.

Diaz, M.N., Frei, B., and Keaney, J.F., Jr. (1997). Antioxidants and atherosclerotic heart disease. New Engl. J. Med., 337, 408-416.

Engelhart, M.J., Geerlings, M.I., Ruitenberg, A., van Swieten, J.C., Hofman, A., Witteman, J.C.M., and Breteler, M.M.B. (2008). Dietary intake of antioxidants and risk of Alzheimer disease. JAMA, 287, 32233229.
Ghimeray, A.K., Sharma, P., Phoutaxay, P., Salitxay, T., Woo, S.H., Park, S.U., and Park, C.H. (2014). Far infrared irradiation alters total polyphenol, total flavonoid, antioxidant property and quercetin production in tartary buckwheat. J. Cereal Sci., 59, 167-172.

Griffith, J.Q., Couch, J.F., and Lindauer, A. (1944). Effect of rutin on increased capillary fragility in man. Proceedings of the Society for Exp. Biol. Med., 55, 228-229.

Guo, X.D., Ma, Y.J., Parry, J., Gao, J.M., Yu, L.L, and Wang, M. (2011). Phenolics content and antioxidant activity of tartary buckwheat from different locations. Molecules, 16, 9850-9867.

Hsu, C.L., Wu, C.H., Huang, S.L., and Yen, G.C. (2009). Phenolic compounds rutin and 0 -coumaric acid ameliorate obesity induced by high-fat diet in rats. J. Agric. Food Chem., 57, 425-481.

Ishiguro, K., Yahara, S., and Yoshimoto, M. (2007). Changes in polyphenolic content and radical-scavenging activity of sweetpotato (Ipomoea batatas L.) during storage at optimal and low temperatures. J. Agric. Food Chem., 55, 10773-10778.

Jiang, P., Burczynski, F., Campbell, C., Pierce, G., Austria, J.A., and Briggs, C.J. (2007). Rutin and flavonoid contents in three buckwheat species Fagopyrum esculentum, F. tataricum, and F. homotropicum and their protective effects against lipid peroxidation. Food Res. Int., 40, 356-364.

Kawakami, A., Kayahara, H., and Ujihara, A. (1995). Properties and elimination of bitter components derived from Tartary buckwheat (Fagopyrum tataricum) flour. Nippon Shokuhin Kagaku Kogaku, Kaishi, 42, $892-898$ (in Japanese).

Kreft, I., Fabjan, N., and Yasumoto, K. (2006). Rutin content in buckwheat (Fagopyrum esculentum Moench) food materials and products. Food Chem., 98, 508-512.

Li, Y.Q., Zhou, F.C., and Gao, F. (2009). Comparative evaluation of quercetin, isoquercetin and rutin as inhibitors of alpha-glucosidase. $J$. Agric. Food Chem., 57, 11463-11468.

Matsubara, Y., Kumamoto, H., Iizuka, Y., Murakami, T., Okamoto, K., Miyake, H., and Yokoi, K. (1985). Structure and hypotensive effect of flavonoid glycosides in Citrus unshiu peelings. Agric. Biol. Chem., 49, 909-914.

Mikami-Konishida, I., Murakami, S., Nakanishi, K., Takahashi, Y., Yamaguchi, M., Shioya, T., Watanabe, J., and Hino, A. (2013). Antioxidant capacity and polyphenol content of extracts from crops cultivated in Japan, and the effect of cultivation environment. Food Sci. Technol. Res., 19, 69-79.

Ohara, T., Ohinata, H., Muramatsu, N., and Matsuhashi, T. (1989). Determination of rutin in buckwheat foods by high performance liquid chromatography. Nippon Shokuhin Kogyo Gakkaishi, 36, 114-120 (in Japanese).

Panchal, S.K., Poudyal, H., Arumugam, T.V., and Brown, L. (2011). Rutin attenuates metabolic changes, nonalcoholic steatohepatitis, and cardiovascular remodeling in high-carbohydrate, high-fat diet-fed rats. $J$. Nutr., 141, 1062-1069.

Qu, Y., Yasuda, T., Nakajima, K., Hiwatashi, A., Moroi, C, Sanada, H., and Egashira, Y. (2013). Effect of rutin in buckwheat noodle on lipid 
metabolism in rats. Food Sci. Technol. Res., 19, 1011-1018.

Shanno, R. (1946). Rutin: A new drug for the treatment of increased capillary fragility. Am. J. Med. Sci., 211, 539-543.

Suzuki, T., Honda, Y., Funatsuki, W., and Nakatsuka, K. (2002). Purification and characterization of flavonol 3-glucosidase, and its activity during ripening in tartary buckwheat seeds. Plant Sci., 163, 417423.

Suzuki, T., Morishita, T., Mukasa, Y., Takigawa, S., Yokota, S., Ishiguro, K., and Noda, T. (2014a). Discovery and genetic analysis of non-bitter Tartary buckwheat (Fagopyrum tataricum Gaertn.) with tracerutinosidase activity. Breeding Sci., 64, 339-343.

Suzuki, T., Morishita, T., Mukasa, Y., Takigawa, S., Yokota, S., Ishiguro, K., and Noda, T. (2014b). Breeding of 'Manten-Kirari', a non-bitter and trace-rutinosidase variety of Tartary buckwheat (Fagopyrum tataricum Gaertn.). Breeding Sci., 64, 344-350.

Suzuki, T., Morishita, T., Takigawa, S., Noda, T., and Ishiguro, K. (2015). Characterization of rutin-rich bread made with 'Manten-Kirari', a tracerutinosidase variety of Tartary buckwheat (Fagopyrum tataricum Gaertn.). Food Sci Technol., 21, 733-738.

Takebayashi, J., Oki, T., Watanabe, J., Yamasaki K., Chen J., SatoFurukawa, M., Tsubota-Utsugi, M., Taku, K., Goto, K., Matsumoto, T., and Ishimi, Y. (2013). Hydrophilic antioxidant capacities of vegetables and fruits commonly consumed in Japan and estimated average daily intake of hydrophilic antioxidants from these foods. J. Food Compos. Anal., 29, 25-31.

Watanabe, J., Oki, T., Takebayashi, J., Yamasaki, K., and Tsushida, T. (2009). Approaches to establish the standardized methods for the determination of antioxidant capacities of foodstuffs. Kagaku to Seibutsu, 47, 237-243 (in Japanese).

Watanabe, J., Oki, T., Takebayashi, J., Yamasaki, K., Takano-Ishikawa, Y., Hino, A., and Yasui, A. (2012). Method validation by interlaboratory studies of improved hydrophilic oxygen radical absorbance capacity methods for the determination of antioxidant capacities of antioxidant solutions and food extracts. Anal. Sci., 28, 159-165.

Wieslander, G., Fabjan, N., Vogrincic, M., Kreft, I., Janson, C., SpetzNyström, U., Vombergar, B., Tagesson, C., Leanderson, P., and Norbäck D. (2011). Eating buckwheat cookies is associated with the reduction in serum levels of myeloperoxidase and cholesterol: A double blind crossover study in day-care center staffs. Tohoku J. Exp. Med., 225, 123130.

Wieslander, G., Fabjan, N., Vogrincic, M., Kreft, I., Vombergar B., and Norbäck, D. (2012). Effect of common and tartary buckwheat consumption on mucosal symptoms, headache and tiredness: A doubleblind crossover intervention study. J. Food Agric. Environ., 10, 107-110.

Wu, X., Beecher, G.R., Holden, J.M., Haytowitz, D.B., Gebhardt, S.E., and Prior, R.L. (2004). Lipophilic and hydrophilic antioxidant capacities of common foods in the United States. J. Agric. Food Chem., 52, 40264037.

Xu, F.Y., Gao, Q.H., Ma, Y.J., Guo, X.D., and Wang, M. (2014). Comparison of tartary buckwheat flour and sprouts steamed bread in quality and antioxidant property. J. Food Quality, 37, 318-328.

Yasuda, T., Masaki, K., and Kashiwagi, T. (1992). An enzyme degrading rutin in Tartary buckwheat seeds. Nippon Shokuhin Kogyo Gakaishi., 39, 994-1000 (in Japanese).

Yasuda, T. and Nakagawa, H. (1994). Purification and characterization of rutin-degrading enzymes in Tartary buckwheat seeds. Phytochem., 37, 133-136

Zhou, X.L., Hao, T.F., Zhou, Y.M., Tang, W., Xiao, Y., Meng, X.X., and Fang, X. (2015). Relationships between antioxidant compounds and antioxidant activities of tartary buckwheat during germination. J. Food Sci. Tech. Mys., 52, 2458-2463.

Zielinski, H., Michalska, A., Amigo-Benavent, M., Del Castillo, M.D., and Piskula, M.K. (2009). Changes in protein quality and antioxidant properties of buckwheat seeds and groats induced by roasting. J. Agric. Food Chem., 57, 4771-4776. 